\title{
HEAT TRANSFER AND PRESSURE DROP PREDICTION IN AN IN-LINE FLAT TUBE BUNDLE BY RADIAL BASIS FUNCTION NETWORK
}

\author{
Tahseen Ahmad Tahseen ${ }^{1, *}$, M.M. Rahman ${ }^{2,3}$ and M. Ishak ${ }^{2,3}$ \\ 1,*Department of Mechanical Engineering, College of Engineering, \\ Tikrit University, Tikrit, Iraq \\ ${ }^{2}$ Faculty of Mechanical Engineering, University Malaysia Pahang \\ 26600 Pekan, Pahang, Malaysia \\ Phone: +609-424-2246; Fax: +609-424-2202 \\ ${ }^{3}$ Automotive Engineering Centre, Universiti Malaysia Pahang, \\ 26600 Pekan, Pahang, Malaysia \\ *E-mail: tahseen@tu.edu.iq
}

\begin{abstract}
This paper aims to predict the heat transfer and pressure drop for an in-line flat tubes configuration in a cross-flow using an artificial neural network. The numerical study of a two-dimensional steady state and incompressible laminar flow for an in-line flat tube configuration in a cross-flow is also considered in this study. The Reynolds number varies from 10 to 320 . Heat transfer coefficient and pressure drop results are presented for tube configurations at three transverse pitches of 2.5, 3.0, and 4.5 with two longitudinal pitches of 3.0 and 6.0. The predicted results for the average Nusselt number and dimensionless pressure show good agreement with previous work. The accuracy between the actual values and the neural network approach model results was obtained with a mean absolute relative error less than $4.1 \%, 4.8 \%$, and $3.8 \%$ for the average Nusselt number, dimensionless pressure drop and average friction factor, respectively.
\end{abstract}

Keywords: In-line flat tube; finite volume technique; modelling; radial basis function network.

\section{INTRODUCTION}

The fluids flow and heat transfer in tube banks symbolize an idealization of many industrially significant processes. Tube bundles are widely employed in cross-flow heat exchangers, but the design is still based on empirical correlations of heat transfer and pressure drop $[1,2]$. Heat exchangers with tube banks in a cross-flow are of great practical interest in many thermal and chemical engineering processes [3-6]. Flat tube designs have been newly introduced for use in modern heat exchanger applications such as automotive radiators. Flat tubes seem to have more appropriate pressure drop characteristics than circular tubes [7]. The forced convection heat transfer over a bundle of circular cylinders was investigated numerically [8-11] and non-square tubes in both in-line and staggered tube arrangements [12-16]. The flow over a bank of elliptical cylinder tubes was presented by Yianneskis et al. [17], both numerically and experimentally. Tahseen et al. [18-20] did numerical studies on incompressible, steady state flow and using the body fitted coordinate (BFC). The studies were based on heat transfer over a staggered two flat tube arrangement. The second study investigated heat transfer over a series of flat tubes between two parallel plates and a third study was of 
heat transfer over an in-line circular tube bank. The three studies show the effect of the Reynolds number on the Nusselt number, which increases with increase of the Reynolds number.

Artificial neural networks have been used in many engineering applications because they provide better and more reasonable solutions [21, 22]. A feed-forward back-propagation ANN was used by Ermis et al. [23] to analyse the heat transfer of a phase change process in and around a finned tube in a study that was both numerical and experimental. The mean relative error was $5.58 \%$ for the experimental study while for the numerical model it was $14.99 \%$. Fadare and Fatona [24]] studied ANNs in the modelling of a staggered multi-row, multi-column, cross-flow, tube-to-tube heat exchanger and the experimental data for air flow over a bundle of tubes. Their results show that the mean absolute relative error is less than $4 \%$ and $1 \%$ for the test and training data sets, respectively. Islamoglu and Kurt [25] used the ANNs model for heat transfer in a corrugated channel. The error between the experimental results and ANNs approached an approximation of the mean absolute relative error of less than $4 \%$. In a recent study, Tahseen et al. [26] numerically analysed the thermal and fluid characteristics of airflow in an in-line configuration of flat tube bundles. The neurofuzzy inference system (ANFAS) model was used to predict the coefficient of heat transfer and pressure drop. The results are shown in the form of streamline, temperature contours, average Nusselt number, and dimensionless pressure drop. The key results show that the average deviation between the numerical and ANFIS model values for average Nusselt number is $1.90 \%$, and the dimensionless pressure drop is $2.97 \%$.

Therefore, this study also focused on the applicability of the Radial Basis Function Network method for analysis of heat transfer and pressure drop in an in-line flat tube bank utilized in the design of heat exchangers to promote heat transfer.

\section{MATHEMATICAL FORMULATION}

There are four isothermally heated horizontal flat tubes in a row. The flat tubes have two diameters, the transverse, $d_{\mathrm{T}}$ and the longitudinal, $d_{\mathrm{L}}$, and the surface temperature of tube $T_{\mathrm{s}}$ is placed in the velocity $u_{\mathrm{in}}$ and the uniform inlet free stream of temperature $T_{\text {in }}$ in the in-line arrangements. The longitudinal pitch-to-small diameter ratio $P_{\mathrm{L}}=P_{1} / d_{\mathrm{T}}$ gives 3.0 and 6.0, while the transverse pitch-to-small diameter ratio $P_{\mathrm{T}}=P_{2} / d_{\mathrm{T}}$ values are 2.5, 3.5 and 4.5. The flat tube should be long enough so that the end effect of the tube can be neglected. Therefore the flow field can be assumed to be two-dimensional. The configurations flow and calculated fields in the flow over the in-line flat tube bank are shown in Figure 1(a).

The governing equations were transformed into dimensionless form upon incorporating the following non-dimensional variables:

$$
\left.\begin{array}{lll}
(X, Y)=\frac{(x, y)}{D_{\mathrm{h}}}, & P=\frac{p}{\rho \times\left(u_{\mathrm{in}}\right)^{2}}, \quad(U, V)=\frac{(u, v)}{u_{\mathrm{in}}} \\
\theta=\frac{T-T_{\mathrm{in}}}{T_{\mathrm{s}}-T_{\mathrm{in}}}, & \operatorname{Re}=\frac{u_{\mathrm{in}} \times D_{\mathrm{h}}}{v}, \quad \operatorname{Pr}=\frac{\mu \times c_{P}}{k}
\end{array}\right\}
$$

where $(x, y)$ are the Cartesian coordinates, $\mathrm{m} ; \rho$ the air density, $\mathrm{kg} / \mathrm{m}^{3} ; p$ pressure, $\mathrm{N} / \mathrm{m}^{2}$; $u_{\text {in }}$ the inlet velocity of air, $\mathrm{m} / \mathrm{s} ;(u, v)$ the fluid velocity, $\mathrm{m} / \mathrm{s} ; T$ fluid temperature, ${ }^{\circ} \mathrm{C} ; T_{\text {in }}$ inlet free stream temperature, ${ }^{\circ} \mathrm{C} ; T_{\mathrm{s}}$ surface temperature of the tube, ${ }^{\circ} \mathrm{C} ; D_{\mathrm{h}}$ hydraulic 
diameter of the tube, $\mathrm{m} ; \mu$ the air dynamic viscosity, $\mathrm{kg} / \mathrm{m} \mathrm{s} ; c_{P}$ the air specific heat $\mathrm{J} /(\mathrm{kg} \mathrm{K})$ and $k$ the air thermal conductivity $\mathrm{W} /(\mathrm{m} \mathrm{K})$.

In developing the model, the following assumptions were made: (i) the physical properties of air flow are constant; (ii) the air flow is incompressible and laminar; and (iii) the flow and heat transfer are steady state. The governing equations for twodimensional continuity, Navier-Stokes for momentum, and energy equation can be written as follows [4]:

The continuity equation:

$$
\nabla \cdot \mathrm{v}=0
$$

Momentum (Navier-Stokes) equation:

$$
\rho \nabla(\mathrm{v} v)=-\nabla P+\mu \nabla \cdot(\nabla \mathrm{v})
$$

Energy equation:

$$
\nabla(\mathrm{v} \mathrm{T})=\frac{k}{\rho c_{P}} \nabla \cdot(\nabla \mathrm{T})
$$

In Eqs. (2) and (3), v is the velocity vector $(u, v)$.

The physical system considered in the present study is displayed in Figure 1(a). The boundary conditions used for the solution domain are uniform inlet velocity, fully developed outflow, and a combination of symmetry and no-slip tube surfaces on the bottom and top boundaries. To complete the formulation of the issue, the boundary conditions are determined to simplify the two-dimensional solution domain, as illustrated in Figure 1(a). The boundary conditions can be summarised as below:

The entrance to the domain: $U=1, \quad V=\theta=0$

Symmetric lines:

$$
\partial U / \partial Y=0, \quad V=0, \quad \partial \theta / \partial Y=0
$$

The exit from the domain: $\quad \partial U / \partial X=0, \partial V / \partial X=0, \quad \partial \theta / \partial X=0$

The surface of tubes: $\quad U=0, \quad V=0, \theta=1$

The set of conservation Eqs. (2) to (4) can be re-written in general form in Cartesian coordinates as Eq. (5):

$$
\frac{\partial(U \phi)}{\partial X}+\frac{\partial(V \phi)}{\partial Y}=\frac{\partial}{\partial X}\left(\Gamma \frac{\partial \phi}{\partial X}\right)+\frac{\partial}{\partial Y}\left(\Gamma \frac{\partial \phi}{\partial Y}\right)+S_{\phi}
$$

The continuity equation, Eq. (2), has no diffusion and source terms. It will be used to derive an equation for the pressure correction. The grid generation scheme based on elliptic partial differential equations is used in the present study to generate the 
curvilinear coordinates. Eq. (5) can be transformed from the physical domain to the computational domain according to the following transformation $\zeta=\zeta(x, y), \eta=\eta(x, y)$ [27]. The schematic of the computational grid is illustrated in Figure 1(b).

The final form of the transformed equation can be written as Eq. (6):

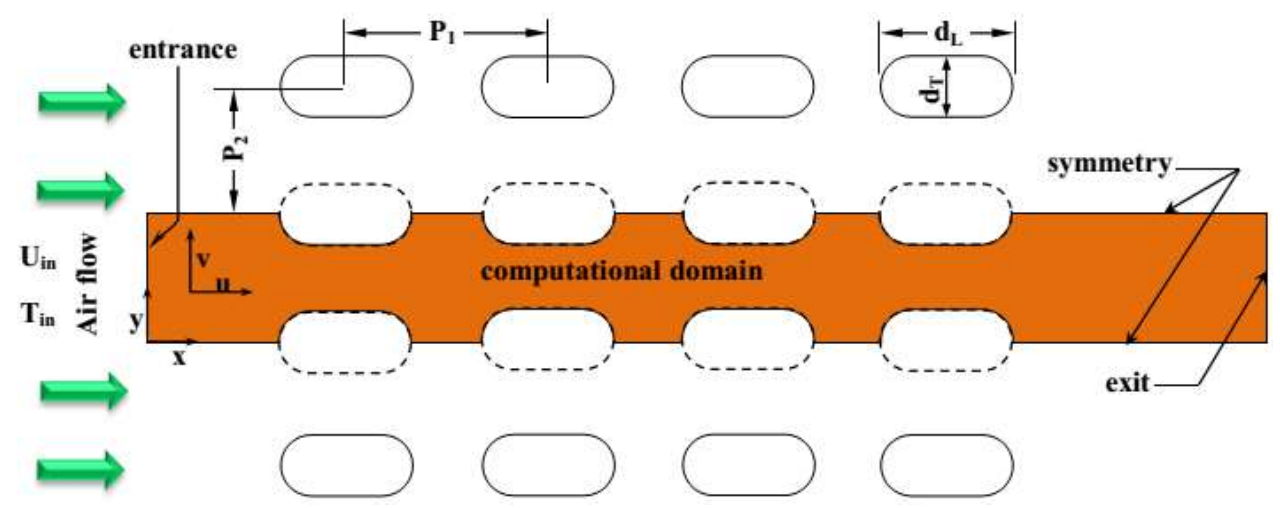

(a)

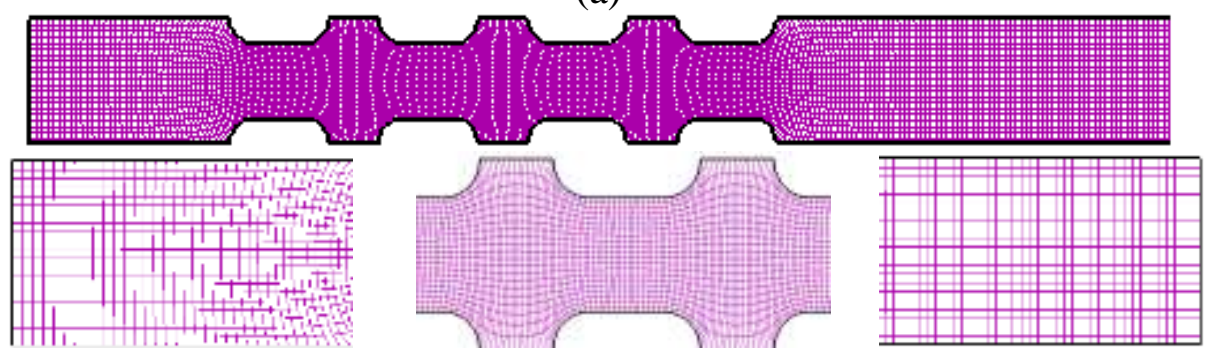

Entrance domain

Inner (main) domain

Exit domain

(b)

Figure 1. In-line flat tube bank: (a) Tube arrangement and computational domain;

(b) Schematic of computational grid systems generated by the body-fitted coordinates.

$$
\frac{\partial}{\partial \zeta}\left(\phi G_{1}\right)+\frac{\partial}{\partial \eta}\left(\phi G_{2}\right)=\frac{\partial}{\partial \zeta}\left(\frac{\Gamma}{J}\left(\alpha \frac{\partial \phi}{\partial \zeta}-\gamma \frac{\partial \phi}{\partial \eta}\right)\right)+\frac{\partial}{\partial \eta}\left(\frac{\Gamma}{J}\left(\beta \frac{\partial \phi}{\partial \eta}-\gamma \frac{\partial \phi}{\partial \zeta}\right)\right)+J \times S_{\phi}
$$

They are expressed as:

$$
\left.\begin{array}{ll}
G_{1}=U \frac{\partial Y}{\partial \eta}-V \frac{\partial X}{\partial \eta}, & G_{2}=V \frac{\partial X}{\partial \zeta}-U \frac{\partial Y}{\partial \zeta}, \\
J=\left(\frac{\partial X}{\partial \zeta} \frac{\partial Y}{\partial \eta}-\frac{\partial Y}{\partial \zeta} \frac{\partial X}{\partial \eta}\right), & \alpha=\left(\frac{\partial x}{\partial \eta}\right)^{2}+\left(\frac{\partial y}{\partial \eta}\right)^{2}, \\
\gamma=\left(\frac{\partial x}{\partial \zeta} \frac{\partial x}{\partial \eta}\right)+\left(\frac{\partial y}{\partial \zeta} \frac{\partial y}{\partial \eta}\right), & \beta=\left(\frac{\partial x}{\partial \zeta}\right)^{2}+\left(\frac{\partial y}{\partial \zeta}\right)^{2}
\end{array}\right\}
$$

In this study, the finding of the overall pressure drop and Nusselt number for the resulting air flow and temperature fields are the total pressure drop for the flat tube bank 
system is represented using an average friction factor, $f_{\mathrm{c}}$ and average Nusselt number, $\overline{\mathrm{Nu}}$ [12] defined as:

$$
\begin{array}{r}
\overline{N u}=\frac{\bar{h} \times D_{\mathrm{h}}}{k} \\
f_{\mathrm{c}}=\frac{\left(p_{\text {in }}-p_{\text {out }}\right)}{2 \times \rho \times\left(u_{\text {in }}\right)^{2} \times N_{\mathrm{L}}}
\end{array}
$$

where $N_{\mathrm{L}}$ is the number of tubes in depth of row.

\section{NUMERICAL METHODS}

The governing equations are solved numerically using FORTRAN 95. The computer code solved the equation of continuity, momentum and energy discretized using a finitevolume technique based on a non-orthogonal coordinate system with Cartesian velocity components and a non-staggered (collocated) grid [29] with the co-operation of the SIMPLE algorithm $[17,30]$. These have been monitoring the convergence to steady state using determination of iterator-to iterator variations of a field variable normalized by its domain. The normalized maximum root mean square (RMS) is defined as:

$$
\mathrm{RMS}=\frac{\left|\chi_{\text {new }}-\chi_{\mathrm{old}}\right|}{\left(\chi_{\mathrm{max}}-\chi_{\mathrm{min}}\right)}
$$

where $\chi$ was $U, V, P$, and $\theta$. The value of RMS was checked in all the nodal locations and convergence was announced when the upper values of RME were typically less than $1 \times 10^{-4}$. The numerical model was validated with some of the previously published standard problems. The comparison between the code results and Bahaidarah et al. [3] is shown in a previous publication by Tahseen et al. [26].

\section{CALCULATION PROCEDURE FOR THE GENERALIZED RADIAL BASIS FUNCTIONS NEURAL NETWORKS}

The artificial neural network is an information processing system that has certain properties in a joint performance with biological neural networks. Artificial neural networks are one of the most commonly used and developed models to investigate the relationship between linear or non-linear input-output patterns. Moreover, they try to circulate a training set and then approximate the test team. Performance is measured using RBFN with predictable success. There is a lot of literature giving detailed ANN types related with function approximation. Schematic diagrams for some artificial intelligence models used in the analysis are shown in Figure 2. The neural networks use the MATLAB program and all the tests have been implemented on a computer. Activation of the error function used in this study is a function of the logistic sigmoid and standard total of squared error function. 
The data was evaluated numerically in this study and normalized in order to get the values. The formula used is as follows:

$$
\frac{\text { Actual value }- \text { Minimum }}{\text { Maximum }- \text { Minimum }} \times(\text { High }- \text { Low })+\text { Low }
$$

where maximum is the maximum data value, minimum is the minimum data value, low is the minimum normalized data value $=0.1$, and high is the maximum normalized data value $=0.9[32]$.

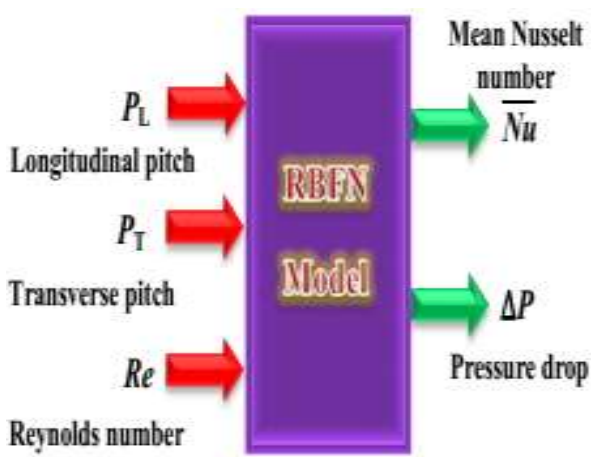

(a)

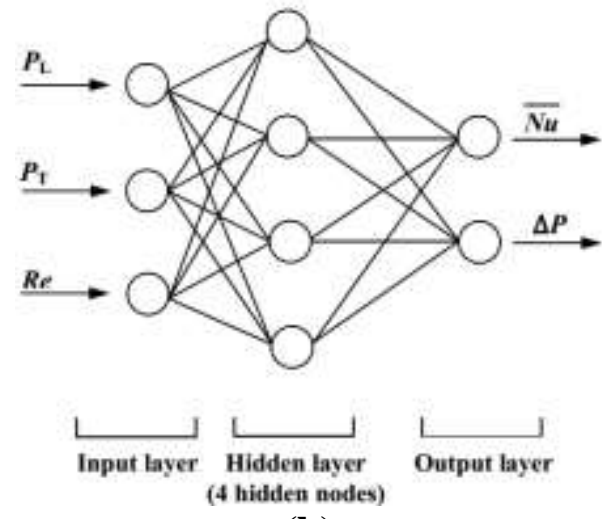

(b)

Figure 2. Schematic of system models: (a) input and output; (b) the radial basis functions neural networks.

\section{RESULTS AND DISCUSSION}

Analysis of the numerical performances was conducted to verify the results from the RBFN model. Sixty numerical simulation data were used to construct the RBFN model. To improve the proposed model, twenty data (about $2 / 3 \times 100 \%$ ) were used for training and ten data the remainder for testing performance (about 100/3\%) were used to test the RBFN model.

The relative error (RE) for variable $B$ and the mean relative error [33] are estimated by Eq. [34] [35]:

$$
\mathrm{RE} \%=\frac{\left|B_{\text {Num }}-B_{\text {Pred }}\right|}{B_{\text {Num }}} \times 100, \quad \text { MRE } \%=\frac{1}{N} \sum_{\mathrm{i}=1}^{\mathrm{N}}(\mathrm{RE} \%)_{\mathrm{i}}
$$

where Num, Pred and $N$ stand for the numerical values, predicted values and the number of numerical data, respectively.

The relative error results of the ANN model for average Nusselt number, dimensionless pressure drop and average friction factor are presented in Figure 3 for the training data. The maximum absolute relative error for the average Nusselt number, dimensionless pressure drop and average friction factor are $\pm 7.109 \%, \pm 8.104 \%$, and $\pm 6.321 \%$, respectively. The regressive model versus predicted (neural network) model heat transfer coefficient in the flat tube banks with the radial basis function as well as the dimensionless pressure drop and average friction factor are good agreement. 
The comparison of the numerical Nusselt number, dimensionless pressure drop and average friction factor with those from various radial basis function methods of training groups are presented in Figure 4. The result shows that the predicted values are in good agreement with numerical values. It can be clearly seen from Figure 4(a) that the predicted set values remained with a maximum relative error $\pm 7.11 \%$ of the available data for average Nusselt number. In addition, the maximum relative error for dimensionless pressure drop and average friction factor is $\pm 8.10 \%$ and $\pm 6.32 \%$, respectively. Figure 4(b) and (c) presents the performance of the RBFN model for the training data used in the dimensionless pressure drop and average friction factor. On the other hand, the mean relative error is $4.73 \%, 5.02 \%$ and $3.80 \%$, for average Nusselt number, dimensionless pressure drop and average friction factor, respectively. However, the RBFN models appear to perform slightly better. This better performance was shown by the higher coefficient of determination $R^{2}$ value 0.999 vs. 0.995 .

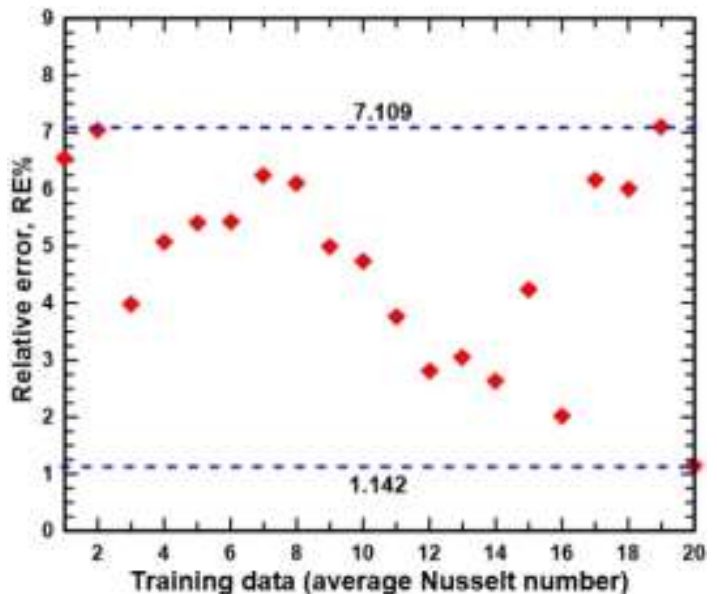

(a)

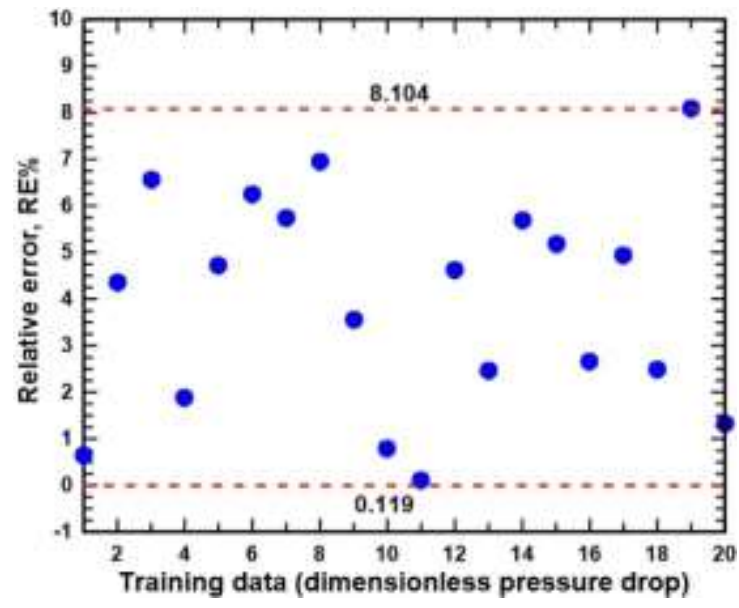

(b)

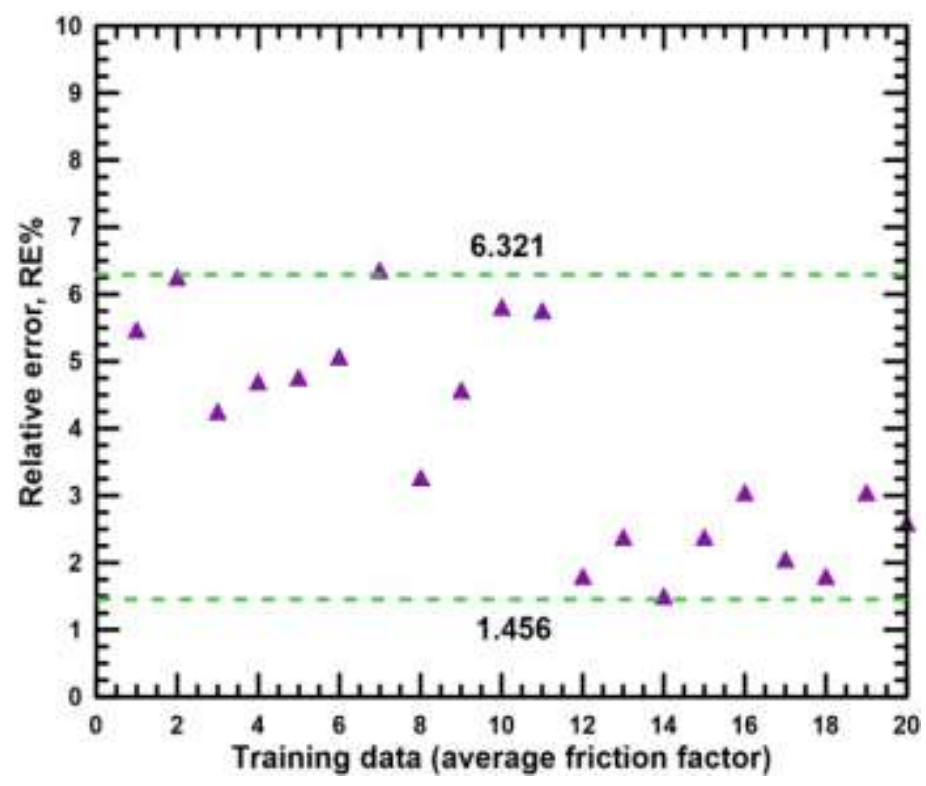

(c)

Figure 3. The relative error for training data using (a) average Nusselt number;

(b) dimensionless pressure drop; (c) average friction factor. 
The numerical values were compared with data obtained by the RBFN, as illustrated in Figure 5 and Table 1. These figures contain the testing data for average Nusselt number, dimensionless pressure drop and average friction factor. Note also that the predicted values are very close to the numerical values with least error. With the best RBFN configuration, the maximum relative errors were around $\pm 7.04 \%, \pm 7.79 \%$, and $\pm 5.12 \%$, and mean absolute relative error was $5.01 \%, 4.38 \%$, and $3.35 \%$, for the average Nusselt number, dimensionless pressure drop and average friction factor, respectively. For the average Nusselt number, dimensionless pressure drop and average friction factor, the predictions of the RBFN were in excellent agreement with the numerical values coefficient of determination, $R^{2}$ value 0.914 vs. 0.999 .

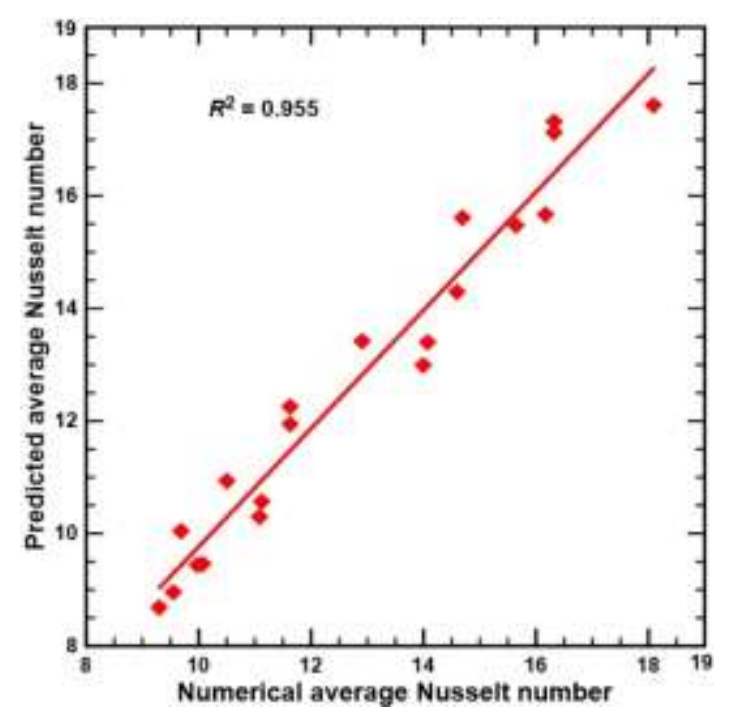

(a)

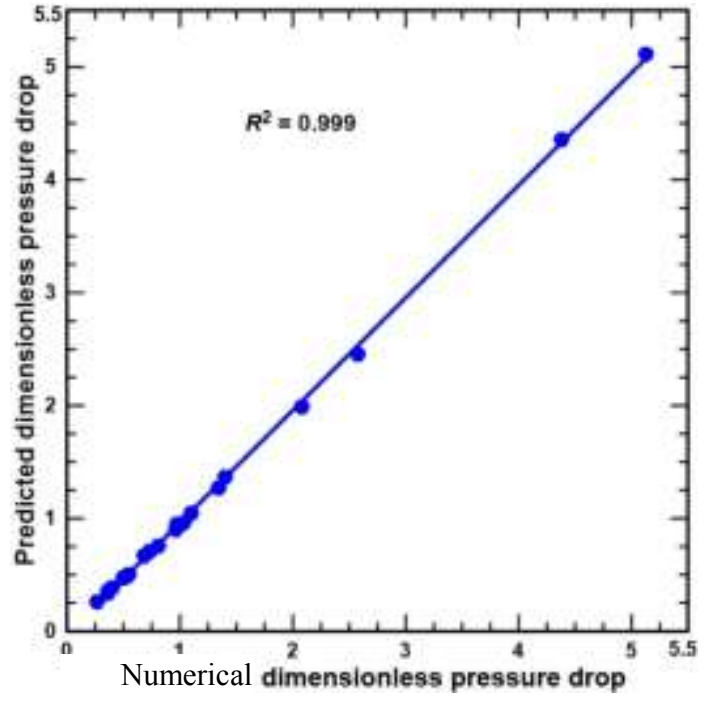

(b)

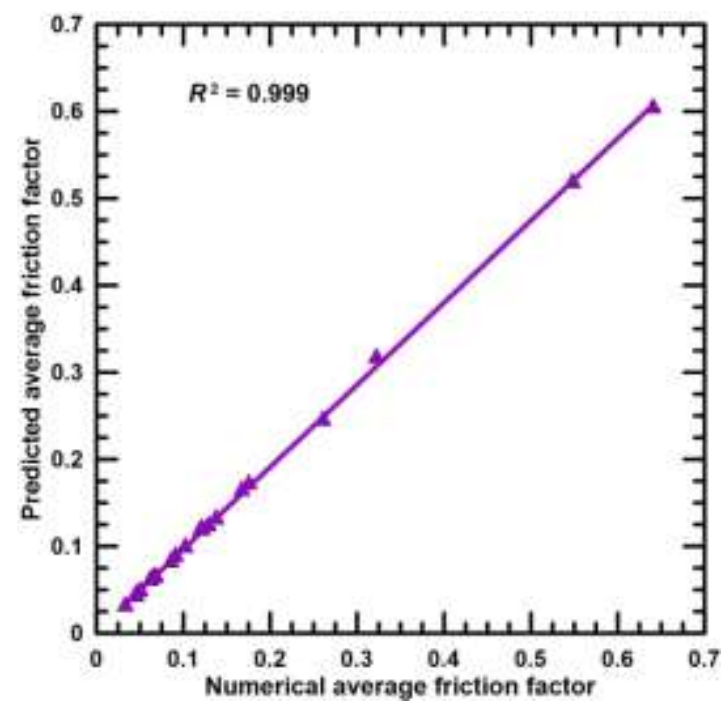

(c)

Figure 4. Scatterplots of the training data for (a) average Nusselt number;

(b) dimensionless pressure drop; (c) average friction factor. 


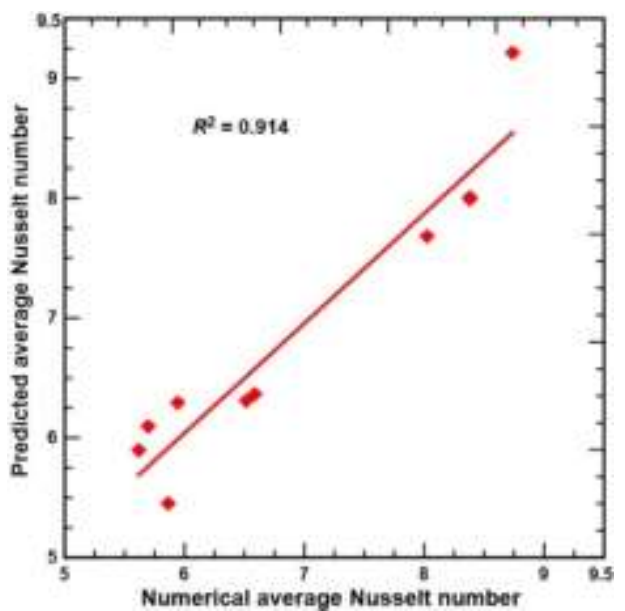

(a)

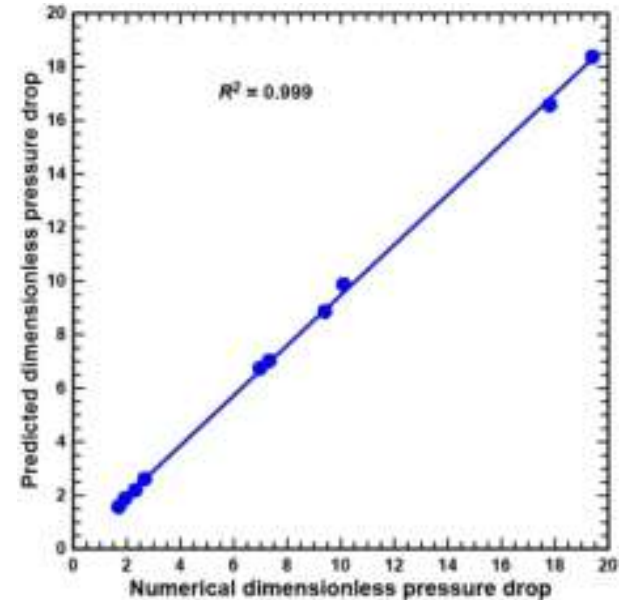

(b)

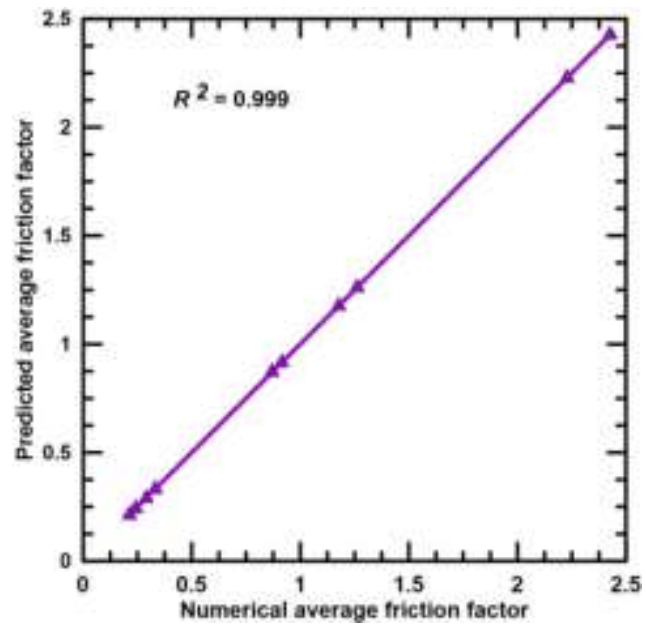

(c)

Figure 5. Scatterplots of the testing data for (a) average Nusselt number; (b) dimensionless pressure drop; (c) average friction factor.

Table 1. Comparison of average Nusselt number and dimensionless pressure drop of ANN model for testing data.

\begin{tabular}{|c|c|c|c|c|c|c|c|c|c|c|}
\hline Run no. & 1 & 6 & 7 & 11 & 12 & 16 & 21 & 22 & 26 & 27 \\
\hline \multicolumn{11}{|c|}{ Average Nusselt number } \\
\hline Numerical & 6.51 & 5.87 & 8.38 & 5.62 & 8.02 & 6.59 & 5.94 & 8.74 & 5.70 & 8.38 \\
\hline RBFN & 6.32 & 5.45 & 7.99 & 5.89 & 7.68 & 6.37 & 6.30 & 9.22 & 6.10 & 8.01 \\
\hline$\% \mathrm{RE}$ & 3.03 & 7.04 & 4.62 & 5.05 & 4.24 & 3.32 & 5.97 & 5.48 & 6.96 & 4.45 \\
\hline$\% \mathrm{MRE}$ & & & & & & 5.02 & & & & \\
\hline \multicolumn{11}{|c|}{ Dimensionless pressure drop } \\
\hline Numerical & 17.82 & 9.41 & 2.32 & 6.97 & 1.71 & 19.41 & 10.10 & 2.67 & 7.32 & 1.93 \\
\hline RBFN & 16.57 & 8.88 & 2.21 & 6.75 & 1.58 & 18.37 & 9.87 & 2.61 & 7.03 & 1.90 \\
\hline$\% \mathrm{RE}$ & 6.99 & 5.63 & 4.54 & 3.14 & 7.79 & 5.39 & 2.27 & 2.18 & 4.04 & 1.88 \\
\hline$\% \mathrm{MRE}$ & & & & & & 4.38 & & & & \\
\hline \multicolumn{11}{|c|}{ Average friction factor } \\
\hline Numerical & 2.23 & 1.18 & 0.29 & 0.87 & 0.21 & 2.43 & 1.26 & 0.33 & 0.96 & 0.24 \\
\hline RBFN & 2.18 & 1.13 & 0.28 & 0.83 & 0.21 & 2.37 & 1.22 & 0.32 & 0.88 & 0.24 \\
\hline$\% \mathrm{RE}$ & 2.05 & 3.67 & 4.21 & 5.03 & 1.23 & 2.46 & 3.012 & 5.124 & 4.321 & 2.342 \\
\hline$\% \mathrm{MRE}$ & & & & & & 3.35 & & & & \\
\hline
\end{tabular}




\section{CONCLUSIONS}

In this article, the model developed used an RBFN to estimate the heat transfer coefficient and pressure drop in a cross-flow over an in-line flat tube bank. The following conclusions were obtained:

i) For the average Nusselt number, the maximum relative error for training is $\pm 7.1 \%$ and the mean relative error is $4.73 \%$. For the testing data the values are $\pm 7.04 \%$ and $5.02 \%$, respectively.

ii) For the dimensionless pressure drop, the maximum relative error for training is $\pm 8.10 \%$ and the mean relative error is $3.96 \%$. For the testing data the values are $\pm 7.79 \%$ and $4.38 \%$, respectively.

iii) For the average friction factor, the maximum relative error for training is $\pm 6.21 \%$ and the mean relative error is $3.80 \%$. For the testing data the values are $\pm 5.12 \%$ and $3.35 \%$, respectively.

iv) The prediction of the average transfer coefficient, dimensionless pressure drop and average friction factor with the RBFN model is in good agreement with the numerical result, and also has a smaller error.

v) Finally, this study clearly shows that the RBFN model is better for predicting the heat transfer rate and pressure drop in an in-line flat tube bank with comprehensive performance.

\section{ACKNOWLEDGEMENTS}

The authors would like to acknowledgements the Universiti Malaysia Pahang for sponsoring the presented work under the FRGS project no. RDU120103.

\section{REFERENCES}

[1] Syam Sundar L, Sharma KV. An experimental study on heat transfer and friction factor of $\mathrm{Al} 2 \mathrm{O} 3$ nanofluid. Journal of Mechanical Engineering and Sciences. 2011;1:99-112.

[2] Suryanarayana KV, Srinivasa Rao G, Reddy Prasad DM, Sharma KV, Sarma PK. Experimental analysis of heat and mass transfer in a packed bed. Journal of Mechanical Engineering and Sciences. 2011;1:124-32.

[3] Bahaidarah HM, Anand N, Chen H. A numerical study of fluid flow and heat transfer over a bank of flat tubes. Numerical Heat Transfer, Part A: Applications. 2005;48:359-85.

[4] Benarji N, Balaji C, Venkateshan S. Unsteady fluid flow and heat transfer over a bank of flat tubes. Heat and mass transfer. 2008;44:445-61.

[5] Kaptan Y, Buyruk E, Ecder A. Numerical investigation of fouling on cross-flow heat exchanger tubes with conjugated heat transfer approach. International Communications in Heat and Mass Transfer. 2008;35:1153-8.

[6] Zukauskas A. Heat transfer from tubes in cross-flow. Advances in heat transfer. 1987;18:87.

[7] Webb RL, Kim N-H. Principl of enhanced heat transfer: New York, Wiley; 1994. 
[8] Jang J-Y, Wu M-C, Chang W-J. Numerical and experimental studies of threedimensional plate-fin and tube heat exchangers. International Journal of Heat and Mass Transfer. 1996;39:3057-66.

[9] Tahseen TA, Ishak M, Rahman MM. Laminar forced convection heat transfer over staggered circular tube banks: A CFD approach. Journal of Mechanical Engineering and Sciences. 2013;4:418-30.

[10] Tahseen TA, Ishak M, Rahman MM. A numerical study of forced convection heat transfer over a series of flat tubes between parallel plates. Journal of Mechanical Engineering and Sciences. 2012;3:271-80.

[11] Rao GS, Sharma KV, Chary SP, Bakar RA, Rahman MM, Kadirgama K, et al. Experimental study on heat transfer coefficient and friction factor of $\mathrm{Al} 2 \mathrm{O} 3$ nanofluid in a packed bed column. Journal of Mechanical Engineering and Sciences. 2011;1:1-15.

[12] Wung T-S, Chen CJ. Finite analytic solution of convective heat transfer for tube arrays in crossflow: Part I-Flow field analysis. Journal of Heat Transfer. 1989;111:633-40.

[13] Tahseen TA, Rahman MM, Ishak M. An experimental study of air flow and heat transfer over in-line flat tube bank. International Journal of Automotive and Mechanical Engineering. 2014;9:1487-500.

[14] Tahseen TA, Ishak M, Rahman MM. Analysis of laminar forced convection of air for crossflow over two staggered flat tubes. International Journal of Automotive and Mechanical Engineering. 2012;6:755-67.

[15] Sahin B, Manay E, Ozceyhan V. Overall heat transfer enhancement of triangular obstacles. International Journal of Automotive and Mechanical Engineering. 2013;8:1278-91.

[16] Ishak M, Tahseen TA, Rahman MM. Experimental investigation on heat transfer and pressure drop characteristics of air flow over a staggered flat tube bank in crossflow. International Journal of Automotive and Mechanical Engineering. 2013;7:900-11.

[17] Versteeg HK, Malalasekera W. An introduction to computational fluid dynamics: the finite volume method: Pearson Education; 2007.

[18] Tahseen TA, Ishak M, Rahman M. Analysis of laminar forced convection of air for crossflow over two staggered flat tubes. International Journal of Automotive and Mechanical Engineering (IJAME). 2012;6:755-67.

[19] Tahseen TA, Ishak M, Rahman M. A numerical study of forced convection heat transfer over a series of flat tubes between parallel plates. Journal of Mechanical Engineering and Sciences (JMES). 2012;3:271-80.

[20] Tahseen TA, Ishak M, Rahman M. A Numerical Study Laminar Forced Convection of Air for In-line Bundle of Cylinders Crossflow. Asian Journal of Scientific Research. 2013;6.

[21] Genel K, Ozbek I, Kurt A, Bindal C. Boriding response of AISI W1 steel and use of artificial neural network for prediction of borided layer properties. Surface and coatings technology. 2002;160:38-43.

[22] Lin T, Tseng C. Optimum design for artificial neural networks: an example in a bicycle derailleur system. Engineering Applications of Artificial Intelligence. 2000;13:3-14.

[23] Ermis K, Erek A, Dincer I. Heat transfer analysis of phase change process in a finned-tube thermal energy storage system using artificial neural network. International Journal of Heat and Mass Transfer. 2007;50:3163-75. 
[24] Fadare D, Fatona A. Artificial neural network modeling of heat transfer in a staggered cross-flow tube-type heat exchanger. The Pacific Journal of Science and Technology. 2008;9:317-23.

[25] Islamoglu Y, Kurt A. Heat transfer analysis using ANNs with experimental data for air flowing in corrugated channels. International Journal of Heat and Mass Transfer. 2004;47:1361-5.

[26] Tahseen TA, Ishak M, Rahman M. Performance predictions of laminar heat transfer and pressure drop in an in-line flat tube bundle using an adaptive neurofuzzy inference system (ANFIS) model. International Communications in Heat and Mass Transfer. 2014;50:85-97.

[27] Thompson JF, Warsi ZU, Mastin CW. Numerical grid generation: foundations and applications: North-holland Amsterdam; 1985.

[28] Manning R, Ewing, J. (2009). .RACQ Vehicles Technologies. Temperatures in cars survey. RACQ Vehicles Technologies. 2009:1-21.

[29] Ferziger JH, Perić M. Computational methods for fluid dynamics: Springer Berlin; 2002.

[30] Patankar S. Numerical heat transfer and fluid flow: CRC Press; 1980.

[31] Papuga J. A survey on evaluating the fatigue limit under multiaxial loading. International Journal of Fatigue. 2011;33:153-65.

[32] Nasr G, Badr E, Joun C. Backpropagation neural networks for modeling gasoline consumption. Energy Conversion and Management. 2003;44:893-905.

[33] Al-Hamamre Z, Al-Salaymeh A. Physical properties of (jojoba oil+biodiesel), (jojoba oil+diesel) and (biodiesel+diesel) blends. Fuel. 2014;123:175-88.

[34] Wang J, Lu M-X, Zhang L, Chang W, Xu L-N, Hu L-H. Effect of welding process on the microstructure and properties of dissimilar weld joints between low alloy and duplex stainless steel. International Journal of Minerals, Metallurgy and Materials. 2012;19:518-24.

[35] Hayati M, Rezaei A, Seifi M. Prediction of the heat transfer rate of a single layer wire-on-tube type heat exchanger using ANFIS. international journal of refrigeration. 2009;32:1914-7.

\section{NOMENCLATURES}

\begin{tabular}{|c|c|c|}
\hline$c_{\mathrm{P}}$ & $\begin{array}{l}\text { specific heat capacity of fluid, } \\
\mathrm{J} /(\mathrm{kg} \mathrm{K})\end{array}$ & $T$ temperature, ${ }^{\circ} \mathrm{C}$ \\
\hline$d_{\mathrm{L}}$ & longitudinal diameter of tube, $\mathrm{m}$ & $u, v \quad$ velocity components, $\mathrm{m} / \mathrm{s}$ \\
\hline$d_{\mathrm{T}}$ & transverse diameter of tube, $\mathrm{m}$ & $U, V$ dimensionless velocity \\
\hline$D_{\mathrm{h}}$ & hydraulic diameter of tube, $\mathrm{m}$ & Cartesian coordinates, $\mathrm{m}$ \\
\hline$f_{\mathrm{c}}$ & Average friction factor & $\begin{array}{ll}X, Y \quad \begin{array}{l}\text { dimensionless Cartesian } \\
\text { coordinates }\end{array}\end{array}$ \\
\hline$G_{1}, G_{2}$ & $\begin{array}{l}\text { contravariant velocity } \\
\text { components }\end{array}$ & Greek symbols \\
\hline$J$ & Jacobian of the transformation & $\alpha, \beta, \gamma$ coefficients of transformation \\
\hline $\bar{h}$ & $\begin{array}{l}\text { average heat transfer coefficient, } \\
\mathrm{W} /\left(\mathrm{m}^{2} \mathrm{~K}\right)\end{array}$ & diffusion coefficient \\
\hline
\end{tabular}




$\begin{array}{llll}k & \begin{array}{l}\text { thermal conductivity of fluid, } \\ \text { W/(m K) }\end{array} & \mu & \text { dynamic viscosity, } \mathrm{kg} /(\mathrm{m} \mathrm{s}) \\ N_{\mathrm{L}} & \text { number of tubes in deep row } & v & \text { kinematic viscosity, } \mathrm{m}^{2} / \mathrm{s} \\ \overline{N u} & \text { average Nusselt number } & \theta & \text { dimensionless temperature } \\ p & \text { pressure, } \mathrm{Pa} & \rho & \text { density, } \mathrm{kg} / \mathrm{m}^{3} \\ P_{1} & \text { longitudinal distance, } \mathrm{m} & \eta, \zeta & \text { curvilinear coordinates } \\ P_{2} & \text { transverse distance, } \mathrm{m} & \phi & \text { general dependent variable } \\ P_{\mathrm{L}} & \text { longitudinal pitch } & \text { Subscripts } & \\ P_{\mathrm{T}} & \text { transverse pitch } & \text { in } & \text { in } \\ P r & \text { Prandtl number } & L & \text { longitudinal } \\ R e & \text { Reynolds number } & \text { out } & \text { out } \\ S & \text { source term } & T & \text { transverse }\end{array}$

